NISTIR 8368

\title{
Ambiguity of the term quantity value in metrology
}

David Flater

This publication is available free of charge from: https://doi.org/10.6028/NIST.IR.8368

National Institute of Standards and Technology U.S. Department of Commerce 
NISTIR 8368

\title{
Ambiguity of the term quantity value in metrology
}

\author{
David Flater \\ Software and Systems Division \\ Information Technology Laboratory
}

This publication is available free of charge from:

https://doi.org/10.6028/NIST.IR.8368

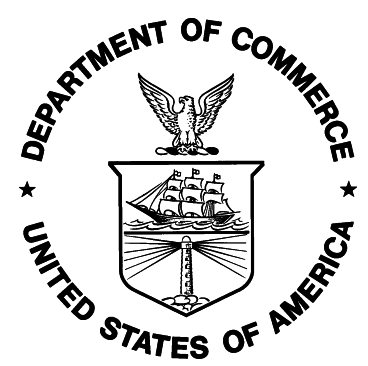

U.S. Department of Commerce Gina M. Raimondo, Secretary

National Institute of Standards and Technology James K. Olthoff, Performing the Non-Exclusive Functions and Duties of the Under Secretary of Commerce for Standards and Technology \& Director, National Institute of Standards and Technology 
Certain commercial entities, equipment, or materials may be identified in this document in order to describe an experimental procedure or concept adequately. Such identification is not intended to imply recommendation or endorsement by the

National Institute of Standards and Technology, nor is it intended to imply that the entities, materials, or equipment are necessarily the best available for the purpose.

The opinions, recommendations, findings, and conclusions in this publication do not necessarily reflect the views or policies of NIST or the United States Government.

National Institute of Standards and Technology Interagency Report 8368 Natl. Inst. Stand. Technol. Interag. Rep. 8368, 24 pages (April 2021)

This publication is available free of charge from: https://doi.org/10.6028/NIST.IR.8368 


\title{
Ambiguity of the term quantity value in metrology
}

\author{
David Flater
}

April 2021

\begin{abstract}
The metrological term quantity value in various forms has conflicting interpretations. Standardization of the vocabulary of metrology has not ended the confusion. This report provides a historical trace of how the inconsistency arose and then describes how it has hindered international standards work, eroded conceptual integrity, and made the communication of software design concepts more difficult.
\end{abstract}

\section{Introduction}

I assume that the reader arrives with a belief that metrological vocabulary is sufficiently mature that the meanings of basic terms would be consistently understood and non-controversial. I present said reader with the following question.

Exhibit $\quad 3 \mathrm{~km} \quad 3000 \mathrm{~m}$

Question How many quantity values is that?

Answers A. One.

B. Two.

C. It depends on the description(s) of the quantity(ies) whose value(s) are being stated.

Having asked this question of a small number of physicists and chemists, I received all three answers in short order.

A review of the historical record suggests that this ambiguity arose organically after different readers of the earliest reference on quantity calculus ascribed different meanings to quantity value. The term has been read in an abstract sense (the algebraic concept), in a concrete sense (the literal expression in terms of a unit), and in a dependent sense (an attribute of some particular quantity). As the practice of quantity calculus became more formalized and standardized, the assumptions underlying these different interpretations were stated explicitly, leading to the present situation where standards conflict with one another or even with themselves.

Few of those questioned believe that this conceptual inconsistency is important enough to justify changes to canonical metrology references; after all, it has not prevented measurements and calibrations from being made every day. But the inconsistency recently led to a breakdown of communication and a great deal of wrangling both in and among national metrology institutes and standards committees. The productivity lost was a cost of inaction that has been incurred and that is likely to reoccur as standards maintenance continues.

Given that a collective will to revise canonical references does not exist at the present time, introducing a new proposal to reconcile and integrate different conceptualizations would only add one more set of definitions to the pile of conflicting contributions. This report therefore refrains from doing that. Instead, it surveys and records the background information needed to work around the issue in the present and potentially to resolve it in the future.

This report is organized as follows. Section 2 covers preliminaries needed for the subsequent sections. Section 3 quotes dictionary definitions of critical words to clarify the plain language basis of metrological jargon. Section 4 provides a historical trace of how the inconsistency arose. Section 5 describes consequences that the inconsistency has had. Section 6 finishes with conclusions. 


\section{Preliminaries}

\subsection{Alternate forms}

The term quantity value appears in multiple forms, as noted in the International Vocabulary of Metrology (VIM) [1, 2, 3]. In English, quantity value also appears in the form value of a quantity and in the short form value when the quantitative context is clear. In French, the only forms are valeur d'une grandeur and valeur. In German, according to a German-language translation of the VIM [4], the forms are Größenwert and Wert einer Größe, but the short form Wert also appears in texts quoted herein.

\subsection{Concepts; denotational semantics}

In order to discuss the issue without going in circles, it is necessary to distinguish and identify the different understandings of quantity value. To accomplish this, I borrow tools from denotational semantics [5, Ch. 5][6], which distinguishes an expression from what it denotes, ${ }^{1}$ but avoid the term value and related words like evaluate that would normally appear in that context.

The following three examples illustrate the meaning of expression and denotation.

- The numeral 3 is an expression that can be printed, displayed on a screen, or spoken out loud. It denotes a particular integer, which is an abstract mathematical concept.

- Analogously, "3 km" is an expression that denotes a particular length.

- The quantity symbol $c$ is an expression that denotes a particular velocity described as the speed of light in vacuum.

Now, we can distinguish three understandings of value that correspond to the three different answers to the question in the introduction:

$V_{A}$ : The expressions " $3 \mathrm{~km}$ " and "3000 m" denote the same value.

$V_{B}$ : Each of the expressions " $3 \mathrm{~km}$ " and "3000 $\mathrm{m}$ " is a distinct value.

$V_{C}$ : If we describe a quantity $l$ as the length on one side of a particular field and say $l=3 \mathrm{~km}=3000 \mathrm{~m}$, then there is only one value. But if we describe a second quantity $l^{\prime}$ as the height of a particular mountain and say $l=3 \mathrm{~km}$ and $l^{\prime}=3 \mathrm{~km}$, then there are two values that happen to be equal. It is immaterial whether $l$ and $l^{\prime}$ are expressed as $3 \mathrm{~km}, 3000 \mathrm{~m}$, or both.

Interpretation $V_{C}$ can be understood as shifting the quantification in the phrase "multiple quantity values" from "multiple (quantity values)" to "(multiple quantity) values."

If we say that the speed of light in vacuum is a special measurand that is defined to have a unique true value, we are using interpretation $V_{A}$ for the value that is further qualified as true. Clearly, the expression of that value is not unique $(299792458 \mathrm{~m} / \mathrm{s}, 299792.458 \mathrm{~km} / \mathrm{s}, 1$ light year per year, etc.). When we say that a plurality of values have historically been assigned to $c$, we can use either $V_{A}$ or $V_{B}$ without contradiction, but $V_{A}$ provides certainty that our information and belief about the velocity have changed. $V_{C}$ raises the question whether the historical assignments characterized the same or different quantities, which is philosophically indeterminate [8].

\footnotetext{
${ }^{1} \mathrm{An}$ alternative presentation of essentially the same distinction is made in $[7, \S 2.2]$.
} 


\subsection{Notes on translation}

German or French text quoted in the following sections is followed immediately by an unofficial translation to English. When an official English version of the text also exists, it is quoted prior to the German or French text and its translation or back-translation to English.

Most published English translations that I have seen of German metrology texts translated Größe to quantity, Wert to value, and Einheit to unit. Obviously, if one imposes an incompatible set of definitions on those words, the result is not what the author intended and it is a bad translation. But as the variable interpretation of terms is the subject of this report, one has to adopt some convention to prevent a vicious cycle in which everything moves and nothing is fixed. So, I have adhered to the described mapping consistently so that readers will have some solid grounds for understanding. In Fleischmann [9], the word Quantität also arises. In that context, translating Größe to quantity and Quantität to either magnitude or amount yields understandable text, but it should be noted that the generally accepted plain language translation of Quantität is quantity. Michell and Ernst [10] translated Hölder's Grösse and Quantität to magnitude and quantity respectively, with quantity intended to signify the more general concept of the two.

The situation is different for French. Recent International Organization for Standardization (ISO) standards have official text in both French and English; in these cases a translation has already been selected and I have not attempted to revise it. But the use of the word grandeur in these standards as a counterpart to the English quantity has been controversial and creates conflicts if it is used when translating Couturat [11] or the Dictionnaire de l'Académie Française [12] to English. Where necessary to avoid confusion, I have chosen a different translation and then included the original French word after it, or simply retained the French word.

Translations from German or French to English were derived with the assistance of Google Translate (translate.google.com) and Microsoft Translator (translate.com). Translations of some of the German text were recycled from an earlier document that was proofread by NIST colleagues Dr. Kenneth Pratt (retired) and Dr. Eite Tiesinga. This acknowledgment is not intended to imply that these reviewers (nor, indeed, the Google and Microsoft translators) would necessarily agree with the translations now appearing in this document.

\subsection{ISO terminology structure}

The year 1984 saw the introduction of the VIM [1], intended to be the authoritative and canonical reference for matters such as the meaning of quantity value. The VIM and several other references quoted in this report formulate definitions in a manner prescribed by ISO 704, Terminology work-Principles and methods [13]. To interpret the definitions as specified, one must be aware of their special structure.

$[13, \S 6.3 .2]$ states: "The definition begins with a predicate noun stating the broader generic (superordinate) concept associated with the concept being defined, together with the delimiters indicating the characteristics that delimit the concept being defined from coordinate concepts." In plain language, this says that a definition should be of the general form " $C: A$ such that $B$," and it means the following:

- Every $C$ is an $A$.

- A particular $A$ is a $C$ only if it meets the additional criteria of $B$.

Explained another way, it means that $C$ is a narrower concept than $A$, and $B$ is the added condition(s) that make it more narrow than $A$. If $B$ is true for every instance of $A$, then $A$ and $C$ are formally indistinguishable and the definition of $C$ is worthless.

A composite $[14, \S 3.40]$ such as the ensemble of number and unit together is defined with a partitive relation rather than a generic relation $[13, \S 5.5 .2 .3]$. The composite can then be referred to as a single concept. This feature of conceptual modelling is widely understood and used outside of ISO terminology work, but the occurrence of a composite in the VIM definition of quantity value has been criticized $[7, \S 2.2][15, \S 5]$. 


\section{Language context}

In the years leading up to Maxwell's publication of A Treatise on Electricity and Magnetism [16], the language of mathematics and measurement already had overlapping senses of the words quantity, magnitude, and value. The following excerpts are from the second edition of the Oxford English Dictionary [17]:

Magnitude, 1.b. In physical sense: Greatness of size or extent.

2.a. Size whether great or small; in geometrical use, the measure or extent of a particular line, area, volume, or angle.

2.b. quasi-concr.

1859 Barn. Smith Arith. \& Algebra (ed. 6) 192 The term Magnitude or Quantity is used in Mathematics to express whatever is capable of increase or diminution. Thus a sum of money is a magnitude or quantity.

Quantity, I.1.a. Size, magnitude, dimensions. ...

4. In the most abstract sense, esp. as the subject of mathematics: That property of things which is involved in the questions 'how great?' or 'how much?' and is determinable, or regarded as being so, by measurement of some kind.

1570 Billingsley Euclid II. i. 62 Two contrary kynds of quantity, quantity discrete or number, and quantity continual or magnitude.

II.12. Math. A thing having quantity (see 4 above); a figure or symbol standing for such a thing.

Value, II.7.a. Math. The precise number or amount represented by a figure, quantity, etc.

1737 Gentl. Mag. VII. 134/2 That he can get a Value of $v$ to substitute in the first Equation, to bring out the Value of $z$ true.

The relevant entry of the current Oxford English Dictionary [18] includes a mixed bag of expressions and their denotations, reflecting the ambiguation of the mathematical sense of the word value:

Value, I.4. Mathematics. A numerical measure of a physical quantity; a number denoting magnitude on some conventional scale; (also) the numerical amount denoted by an algebraic term; the numerical output of a mathematical function.

One could plausibly interpret "These two values have the same value" as a valid utterance using different senses of value for the two occurrences.

In French, there is overlap between quantité, grandeur, and valeur. The following excerpts are from the ninth edition of the Dictionnaire de l'Académie Française [12]:

\section{GRANDEUR}

I. Étendue d'un objet considéré dans une ou plusieurs de ses dimensions (hauteur, largeur, longueur), dans son volume ou sa superficie; taille, dimension.

II. Valeur variable caractérisant l'importance d'un objet, l'intensité d'un phénomène mesurable. ... Par métonymie. SCIENCES. Ce qui peut être mesuré et affecté d'une valeur numérique variable. La longueur, la masse, le temps sont des grandeurs physiques.

\section{QUANTITÉ}

1. Propriété de ce qui est mesurable, de ce qui est susceptible d'accroissement ou de diminution. ... Par métonymie. Ce qui peut être mesuré et exprimé par une valeur numérique, grandeur. ... La quantité de travail, la quantité de chaleur et la quantité d'énergie fournies par un système se mesurent en joules. 


\section{GRANDEUR}

I. The extent of an object considered in one or more of its dimensions (height, width, length), its volume, or area; size, dimension.

II. Variable value characterizing the importance of an object, the intensity of a measurable phenomenon. ... By metonymy: (sciences) That which can be measured and assigned a variable numerical value. Length, mass, time are physical quantities (grandeurs).

\section{QUANTITÉ}

1. Property of what is measurable, of what is likely to increase or decrease. ... By metonymy: What can be measured and expressed by a numerical value; magnitude (grandeur). ... The amount (quantité) of work, the amount of heat and the amount of energy provided by a system are measured in joules.

The ninth edition is a work in progress and does not yet include a definition of valeur. The following excerpt is from the eighth edition [19]:

Valeur, en termes de Mathématiques, désigne Toute quantité exprimée en chiffres ou même algébriquement, et provenant de la résolution d'une ou de plusieurs équations.

Value, in mathematical terminology, refers to any quantity (quantité) expressed in numbers or even algebraically, and coming from the resolution of one or more equations.

Finally, here are the most relevant definitions of Größe, Quantität, and Wert from the current online Duden [20]:

Größe: 2. quantitative und qualitative Eigenschaft oder Merkmal einer physikalischen Erscheinung, das sich in einem zahlenmäßigen Wert ausdrücken lässt (Gebrauch: Physik).

Quantität: 1. a) Menge, Anzahl o. Ä., in der etwas vorhanden ist; Ausmaß, das etwas hat.

Wert: 4. in Zahlen oder Zeichen ausgedrücktes Ergebnis einer Messung, Untersuchung o. Ä.; Zahlenwert.

Quantity (Größe): 2. Quantitative and qualitative property or characteristic of a physical phenomenon that can be expressed in a numerical value (usage: physics).

Quantity (Quantität): Amount, number, or similar in which something is present; extent that something has.

Value: Result of a measurement, examination, or similar expressed in numbers or characters; numerical value.

\section{History}

This survey includes academic works that introduced new concepts and significant standards that promulgated them.

An introductory paragraph from Maxwell [16] was restated in numerous references, notably the early versions of several significant standards. This history attempts to reflect that without belaboring the point with full quotations in every case.

Recent references that duplicate definitions from the VIM are skipped. 


\subsection{Maxwell, 1873}

From the Preliminary of $A$ Treatise on Electricity and Magnetism [16]:

Every expression of a Quantity consists of two factors or components. One of these is the name of a certain known quantity of the same kind as the quantity to be expressed, which is taken as a standard of reference. The other component is the number of times the standard is to be taken in order to make up the required quantity. The standard quantity is technically called the Unit, and the number is called the Numerical Value of the quantity.

The famous paragraph quoted above immediately introduces the expression of a quantity, but does not give a name to the concept.

Maxwell later uses the unqualified term value when referring to the values of quantities, such as in the following paragraph from the end of part 6 :

In transforming the values of physical quantities determined in terms of one unit, so as to express them in terms of any other unit of the same kind, we have only to remember that every expression for the quantity consists of two factors, the unit and the numerical part which expresses how often the unit is to be taken. Hence the numerical part of the expression varies inversely as the magnitude of the unit, that is, inversely as the various powers of the fundamental units which are indicated by the dimensions of the derived unit.

A value is "transformed" when there is a change of unit. Does that make it a different value? If so, the interpretation is $V_{B}$; if not, $V_{A}$. Some readers believe that the text clearly describes a concept consistent with $V_{A}$ [21]; others argue that such an interpretation cannot have been intended [22].

De Boer observed that "Maxwell, although the first to introduce the concept physical quantity, apparently still hesitated to use this new concept explicitly everywhere in the lengthy theoretical calculations in his publications. Important in this connection is also that Maxwell had to cope in his Treatise (1873) with the difficulties of explaining the existence of two different sets of definitions of electric and magnetic quantities and their corresponding unit systems. He chose a description in which the symbols still represent numerical values" [23, §1.1].

\subsection{Helmholtz, 1887}

Helmholtz [24] referred to number-unit pairs as benannte Zahlen, which is most commonly translated as denominated numbers. In current mid-Atlantic English, this meaning of denomination is seldom used except in reference to currency, but the intent is clear through analogy: to know how much money you have, it is not enough to know that you have $n$ bills; you also need to know the denominations of the bills. The units in number-unit pairs fill the same role as the denominations of the bills; they "denominate" the numbers to which they are attached so that you know how much of whatever you have.

Von viel grösserer Bedeutung und ausgedehnterer Anwendung ist das Zählen gleicher Objecte. Solche Objecte, die in irgend einer bestimmten Beziehung gleich sind und gezählt werden, nennen wir die E in h e i t e n der Zählung, die Anzahl derselben bezeichnen wir als eine b e n a n n t e Z a hl, die besondere Art der Einheiten, die sie zusammenfasst, die Benennung der Zahl.

..

Objecte oder Attribute von Objecten, die mit ähnlichen verglichen den Unterschied des grösser, gleich oder kleiner zulassen, nennen wir Grössen. Können wir sie durch eine benannte Zahl ausdrücken, so nennen wir diese den W erth der Grösse, das Verfahren, wodurch wir die benannte Zahl finden, Messung der Grösse. 
Of much greater importance and more extensive application is the counting of same objects. Such objects, which in some particular relation are equal and counted, we call the units of the count, the number of these we call a denominated number, the particular kind of units that it summarizes, the denomination of the number.

$\ldots$

Objects or attributes of objects, that when compared with similar allow the discernment of greater, equal, or lesser, we call quantities. If we can express it by a denominated number, we call this the value of the quantity, the method by which we find the denominated number, measurement of the quantity.

Since the denominated number is expressing a quantity, this passage suggests a preference for interpretation $V_{B}$. Invariance to a change of unit is not discussed.

\subsection{Lodge, 1888}

In a letter that circulated before his brief introduction of quantity calculus, "The multiplication and division of concrete quantities" $[25,26]$ appeared, Lodge explains the concept of invariance to a change of unit $[25$, p. 56]:

... a length is not completely expressed by a number, but by a number $\times$ a standard: e.g. 6 feet $=6 \times$ one foot. Here the 6 and the one foot are two factors, both essential, in the expression of that particular length: and similarly with any other length. I would then suggest that both these factors, the standard and its multiple, should be included in the symbol $s$, in all fundamental equations in which $s$ occurs. And similarly with the other symbols $v, t$, etc. Thus $v$ would have the same value in each of the following expressions: 4 miles an hour, $4 \times 1760$ yards an hour, 5.9 feet a second; whereas, if it were only a number, we should have $v=4$ in the first case, $4 \times 1760$ in the second, and 5.9 in the third.

The phrase " $v$ would have the same value in each of the following expressions" indicates interpretation $V_{A}$ for the term value.

\subsection{Russell, 1903}

$V_{A}$ makes an appearance in Russell's The Principles of Mathematics under the name magnitude [5, Ch. 19]:

An actual foot-rule is a quantity: its length is a magnitude. Magnitudes are more abstract than quantities: when two quantities are equal, they have the same magnitude.

Note the use of magnitude as a count noun ( $a$ magnitude) rather than only the magnitude of some quantity. This use of magnitude is not unique to Russell, but can be traced through the history of terms used in mathematics and measurement in the time before Maxwell.

When Couturat relayed Russell's concepts in 1905, he used quantité for quantity and grandeur for magnitude [11, p. 99].

\subsection{Wallot, 1926}

Wallot [27] uses Wert in passing to refer to values of quantities, but the text is insufficient to resolve $V_{A}$ from $V_{B}$; e.g.:

Der Versuch ist oft ausgeführt worden und hat bezogen auf praktische Einheiten den Wert

ergeben.

$$
\varepsilon_{0}=0,88552 \cdot 10^{-13} \frac{\mathrm{Coul} \mathrm{cm}}{\mathrm{V} \mathrm{cm}^{2}}
$$


The experiment has been carried out many times, and the result has based on practical units the value

$$
\varepsilon_{0}=0.88552 \times 10^{-13} \frac{\text { Coul cm }}{\mathrm{V} \mathrm{cm}^{2}}
$$

Wallot elsewhere calls the product of number and unit a Größe [27, Eqn. 13]:

Es leuchtet unmittelbar ein, daß die Größen als Prod ukt e aus einer „Einheit“, d. h. einer Größe derselben Art, und einem „Zahlenwert“, d. h. einer reinen Zahl, aufgefaßt werden dürfen:

$$
\text { Größe }=\text { Zahlenwert } \cdot \text { Einheit. }
$$

It is immediately obvious that the quantities may be understood as products of a "unit," i.e. a quantity of the same kind, and a "numerical value," i.e. a pure number:

$$
\text { Quantity }=\text { numerical value } \times \text { unit. }
$$

\subsection{DIN 1313, 1931}

The first version of Deutsches Institut für Normung (DIN) standard 1313 [28] continues the trend in which the product of number and unit is equated to a physical quantity (physikalische Größe), a term quantity value is not explicitly introduced, but the unqualified term Wert is used in passing to refer to such without enough context to distinguish $V_{A}$ from $V_{B}$ :

... aus dem Werte von $\varepsilon_{0}$ bequem das Verhältnis der elektrostatischen Elektrizitätsmengeneinheit $[Q]_{s}$ zum Coulomb herleiten.

$\ldots$ from the value of $\varepsilon_{0}$ conveniently derive the ratio of the electrostatic electrical unit $[Q]_{s}$ to the coulomb.

The use of relevant terms in the 1962 version of DIN 1313 [29] is essentially consistent with that of the 1931 version, but the concept of invariance to a change of unit is explained and applied to Größe.

\subsection{Fleischmann, 1960}

The unclear factoring of the terms Größe and Wert was tackled by Fleischmann, who introduced the term Größenwert $[9, \S 5]$ :

Jeder Größenwert läßt sich schreiben als ein Produkt aus einer unbenannten Zahl (»Zahlenwert«, Maßzahl) und einem speziellen Größenwert, der als Einheit verwendet wird. In jedem Fall gilt daher die Gleichung

$$
\text { Größenwert }=\text { Zahlenwert } \cdot \text { Einheit }
$$

Größenwert und Einheit müssen dabei der gleichen Größenart angehören. Der »Zahlenwert« ist diejenige Zahl, mit der man die Einheit multiplizieren muß, um den Größenwert zu erhalten.

Each quantity value can be written as a product of a dimensionless number ("numeric value," measure) and a special quantity value used as a unit. In any case, therefore, the equation holds

$$
\text { Quantity value }=\text { numerical value } \times \text { unit }
$$

The quantity value and the unit must be of the same kind-of-quantity. The "numeric value" is the number by which one must multiply the unit to obtain the quantity value.

Previous text directly explains the different meanings of Größe and Größenwert, and indicates interpretation $V_{A}$ for Größenwert $[9, \S 3]$ : 
Das Wort Größe wird bisher sowohl für Größe mit u n best im m t e r Quantität gebraucht (z. B. eine elektrische Ladung $Q=\lambda \cdot(1 \mathrm{As})$, wo $\lambda$ eine unbenannte Zahl ist, für die gilt: $0<|\lambda|<\infty)$, als auch für Größe mit bestim mter Quantität (z. B. 1,6 $10^{-19}$ As oder z. B. 3 As oder auch 96500 As). Da man das aber auseinanderhalten muß, werden zwei Ausdrücke benötigt. Für Größe mit bestimmter Quantität sagt man »Wert einer Größe« (Größenwert). Der Wert ist invariant gegenüber Einheitenwahl, z. B. $7200 \mathrm{sec}=120 \mathrm{~min}=2 \mathrm{~h}$ ist der nämliche Größenwert (Wert der Größe Zeit $t$ ).

Zur Umschreibung dessen, was »Größenwert« bedeutet, kann man sagen: Merkmalsquantität, Eigenschaftsquantität, Merkmalswert; verschiedentlich habe ich auch dafür gebraucht $»$ Einzelbestimmungsstück « (Wert einer Einzeleigenschaft). Der Merkmalswert ist stets eine Aussage darüber, in welcher Quantität ein Merkmal eines Objekts vorliegt. In einer Größengleichung darf niemals ein Objekt selbst vorkommen (also niemals »Elektron«, »Atom«, »materieller Körper«).

Eine »Größe mit unbestimmter Quantität« (z. B. die Zeit $t$ ) nennt man einfach »Größe«. Man könnte dafür auch sagen »Allgemeingröße«, weil sie allgemein ist hinsichtlich der Quantität. Das ist im Einklang mit einem weit verbreiteten Gebrauch und stimmt überein mit dem Gebrauch von J. Wallot, dem wir die Wiederentdeckung und die systematische Einführung des Rechnens mit Größen verdanken. Die »Größe« hat k e i n en Sachbezug. Sie ist sozusagen eine Abstraktion von der »Sachgröße«, der sachbezogenen Größe mit Objektbindung, die sofort erläutert werden soll.

Auch die Größenwerte bilden eine Struktur im Sinne der Algebra (vgl. dazu Ziffer 21).

The word quantity has thus far been used both for a quantity with a nonspecific, unspecified, or undetermined magnitude (e.g., an electrical charge $Q=\lambda \cdot(1 \mathrm{As})$, where $\lambda$ is a dimensionless number for which the following applies: $0<|\lambda|<\infty)$, and for a quantity with a specific magnitude (e.g., $1.6 \times 10^{-19}$ As or 3 As or $96500 \mathrm{As}$ ). But since these have to be distinguished, two expressions are needed. For a quantity with a specific magnitude one says "value of a quantity" (quantity value). The value is invariant with respect to the choice of units; e.g., $7200 \mathrm{sec}=$ $120 \mathrm{~min}=2 \mathrm{~h}$ is the same quantity value (value of the quantity time $t$ ).

To paraphrase what "quantity value" means, one can say: magnitude of a characteristic, magnitude of a property, value of a characteristic; I have also used "single determinant" (value of a single property) on various occasions. The characteristic value is always a statement about the amount in which a characteristic of an object is present. An object itself must never appear in a quantity equation (thus never "electron," "atom," "material body").

A "quantity with unspecified magnitude" (e.g., the time $t$ ) is simply called a "quantity." One could also say "general quantity" for this because it is general with regard to magnitude. This is consistent with widespread usage and the usage of $J$. Wallot, to whom we owe the rediscovery and systematic introduction of calculating with quantities. The "quantity" has no reference in kind. It is, so to speak, an abstraction of the "material quantity," the relevant quantity with object binding, which is to be explained forthwith.

The quantity values also form a structure in the sense of algebra (see Section 21).

\subsection{Quantities and Units in Clinical Chemistry, 1966}

Quantities and Units in Clinical Chemistry had several editions before it was absorbed by the Silver Book $[30,31,32,33,34]$. I have not acquired the 1964 edition. The 1966 edition echoes Maxwell's Preliminary in which direct reference to quantity value is avoided:

3.1.1. In a group of mutually comparable quantities of exactly the same kind, one of them may be chosen as a reference quantity, which is called a unit. Other quantities of the same kind can be expressed as a product of the unit and a number, called the numerical value of the quantity. Thus,

$$
(\text { quantity })=(\text { numerical value of a quantity }) \times(\text { unit })
$$




\subsection{Quantities and Units in Clinical Chemistry, 1973}

In the 1973 edition [32], the term quantity value still is not introduced, but magnitude is used to mean $V_{A}$ :

3.3. Unit: a chosen reference quantity, which may be used for comparison of quantities of the same dimension. Examples: millimetre (e.g. for lengths), kilogram (e.g. for masses), mole (e.g. for amounts of substance), gram per litre (e.g. for mass concentration or mass densities).

Note: The magnitude of the quantity is not influenced by the choice of unit.

3.4. Numerical value: the number that gives the magnitude of the measured quantity when multiplied by the unit.

$$
\text { Numerical value }=\text { quantity } / \text { unit }
$$

The above text is the same in the 1978 edition [33].

\subsection{DIN 1313, 1978}

Fleischmann's Größenwert was standardized by the 1978 edition of DIN 1313 [35]:

2.1.1 Die qualitative und quantitative Beschreibung physikalischer Phanomene (Körper, Vorgange, Zustande) erfolgt mit phy sikalis chen Größen, im folgenden kurz Größen genannt. Größen - die Skalare, Vektoren oder Tensoren sein können - beschreiben meßbare Eigenschaften. Jeder spezielle Wert einer Größe (der Größenwert, im Bereich der Meßtechnik Meßwert genannt) kann als Produkt ausgedrückt werden:

$$
\text { Größenwert }=\text { Zahlenwert } \cdot \text { Einheit }
$$

$\ldots$

2.1.2 Ein Größenwert ist invariant gegen einen Einheitenwechsel. Zahlenwert und Einheit eines Größenwertes verhalten sich gegenläufig, nämlich wie die Faktoren eines konstanten Produktes. Dies gilt auch beim Übergang zu einem mit einem Vorsatz gebildeten dezimalen Vielfachen oder Teil einer Einheit.

Beispiel: Es handelt sich bei den Angaben $10 \mathrm{~cm}$ und $100 \mathrm{~mm}$ um denselben Größenwert.

2.1.1 The qualitative and quantitative description of physical phenomena (bodies, processes, states) is carried out with physical quantities, hereinafter referred to as quantities. Quantitieswhich can be scalars, vectors, or tensors - describe measurable properties. Any specific value of a quantity (the quantity value, called measurement value in the field of measurement technology) can be expressed as a product:

$$
\text { Quantity value }=\text { numerical value } \times \text { unit }
$$

$\cdots$

2.1.2 A quantity value is invariant with respect to a change of unit. The numerical value and unit of a quantity value move in opposite directions, as the factors of a constant product. This also applies to the conversion to a decimal multiple or submultiple of a unit formed with a prefix.

For example: The values $10 \mathrm{~cm}$ and $100 \mathrm{~mm}$ are the same quantity value.

This excerpt clearly identifies $V_{A}$. In other text, $V_{B}$ is referred to in passing using the word Darstellung, translatable as "presentation" or "representation." 


\subsection{International System of Quantities (ISQ), 1981}

Core concepts are defined in the first part of the International System of Quantities (ISQ). The following text from ISO 31/0-1981(E), "second edition" (1981-07-01) [36], again echoes Maxwell's Preliminary in which direct reference to quantity value is avoided:

If a particular example of a quantity out of such a category is chosen as a reference quantity called the unit, then any other quantity from this category can be expressed in terms of this unit, as a product of this unit and a number. This number is called the numerical value of the quantity expressed in this unit.

\subsection{VIM 1, 1984}

The International Vocabulary of Metrology (VIM) is published in English and French with neither version designated as taking precedence over the other. The following definitions of quantity value are from the first edition, generally known as "VIM 1" [1]:

English:

\section{value (of a quantity)}

The expression of a quantity in terms of a number and an appropriate unit of measurement.

French:

\section{valeur (d'une grandeur)}

Expression d'une grandeur sous la forme d'un nombre et d'une unité de mesure appropriée.

\section{value (of a quantity)}

Expression of a quantity in the form of a number and an appropriate unit of measurement.

By referring to expressions, these definitions clearly indicate interpretation $V_{B}$. For the concept $V_{A}$, there is no term other than simply quantity, which in the French VIM has the corresponding term grandeur.

I have no record of the rationale behind the definition, but observe that if grandeur is interpreted as defined by Couturat [11, p. 99], then $V_{A}$ has already been spoken for.

While later versions of the VIM mention magnitude, some readers consider magnitude to be already present in and inseparable from a quantity, so that there is nothing to talk about other than the quantity and its expression [37]. The definitions in VIM 1 are consistent with such an interpretation.

\subsection{Red Book, 1987}

The Red Book [38] makes reference to the 1981 version of the International System of Quantities [36]. Consistent with that reference, it echoes Maxwell's Preliminary.

The unqualified value arises in Table 9 (1986 recommended values of the fundamental physical constants), which has columns titled Quantity, Symbol, and Value. Some quantities have more than one entry in the Value column. Interpretation $V_{A}$ is easier to apply than $V_{B}$ only because the column heading is "Value" (implying multiple expressions of the same value) not "Values."

The 1987 Red Book remains the current version 34 years later. 


\subsection{VIM 2, 1993}

The following definitions of quantity value are from the second edition of the VIM, generally known as "VIM 2" [2]:

English:

value (of a quantity)

magnitude of a particular quantity generally expressed as a unit of measurement multiplied by a number

French:

valeur (d'une grandeur)

expression quantitative d'une grandeur particulière, généralement sous la forme d'une unité de mesure multipliée par un nombre

value (of a quantity)

Quantitative expression of a particular quantity, generally in the form of a unit of measurement multiplied by a number.

The VIM does not define magnitude. The appearance of this word in the English version of VIM 2 may indicate a desire to assign a term for $V_{A}$ to separate it from the other senses of quantity. However, the French version did not follow and retains interpretation $V_{B}$.

\subsection{DIN 1313, 1998}

The current edition of DIN 1313 [39] was completely rewritten to provide explicit definitions of terms in a form similar to that of the VIM. The interpretation of Größenwert is not immediately obvious from the definition itself, but subsequent text makes it clear that the interpretations of Größenwert $\left(V_{A}\right)$ and Darstellung des Größenwertes $\left(V_{B}\right)$ are consistent with those of the previous edition (see Section 4.10).

\subsection{Größenwert}

Ein der Erscheinungsform der Größe zugeordneter Wert.

...

\subsection{Darstellung von Größenwerten durch Zahlenwert und Einheit} Jeder Größenwert $x$ kann als das Produkt von Zahlenwert und Einheit dargestellt werden. ...

\subsection{Wechsel der Einheit}

Der Größenwert ist gegenüber einem Wechsel der Einheit invariant. Wenn das $\mu$-fache einer Einheit als neue Einheit gewählt wird, so multipliziert sich der zugehörige Zahlenwert mit $1 / \mu$. Aus

$$
x=\{x\}_{\mathrm{e}_{1}} \cdot \mathrm{e}_{1}=\{x\}_{\mathrm{e}_{2}} \cdot \mathrm{e}_{2} \text { und } \mathrm{e}_{2}=\mu \cdot \mathrm{e}_{1} \text { folgt }\{x\}_{\mathrm{e}_{2}}=1 / \mu \cdot\{x\}_{\mathrm{e}_{1}} .
$$

\subsection{Quantity value}

A value assigned to the manifestation of the quantity.

...

\subsection{Representation of quantity values by numerical value and unit}

Each quantity value $x$ can be represented as the product of numerical value and unit. ...

\subsection{Change of unit}

The quantity value is invariant with respect to a change of the unit. If $\mu$ times a unit is chosen as the new unit, the associated numerical value is multiplied by $1 / \mu$. From

$$
x=\{x\}_{\mathrm{e}_{1}} \cdot \mathrm{e}_{1}=\{x\}_{\mathrm{e}_{2}} \cdot \mathrm{e}_{2} \text { and } \mathrm{e}_{2}=\mu \cdot \mathrm{e}_{1} \text { follows }\{x\}_{\mathrm{e}_{2}}=1 / \mu \cdot\{x\}_{\mathrm{e}_{1}} .
$$




\subsection{SI Brochure, 2006}

The International System of Units (SI) Brochure is published in French and English, with the French text designated as the official record.

Although the SI Brochure first appeared in 1970, the text that is relevant for this report first appeared in the 8th edition (2006) [40]. The German-language translation of the relevant text by Physikalisch-Technischen Bundesanstalt (PTB) [41] is shown here below the French and English texts distributed by the International Bureau of Weights and Measures (BIPM). In this case, the English text suffices as a translation of the French and German.

La valeur d'une grandeur est généralement exprimée sous la forme du produit d'un nombre par une unité. L'unité n'est qu'un exemple particulier de la grandeur concernée, utilisé comme référence. Le nombre est le rapport entre la valeur de la grandeur en question et l'unité.

The value of a quantity is generally expressed as the product of a number and a unit. The unit is simply a particular example of the quantity concerned which is used as a reference, and the number is the ratio of the value of the quantity to the unit.

Der Wert einer Größe wird generell als Produkt von Zahlenwert und Einheit ausgedrückt. Die Einheit ist dabei nur ein spezielles Beispiel der betreffenden Größe und wird als Bezug genutzt. Der Zahlenwert ist das Verhältnis zwischen dem Wert der betreffenden Größe und der Einheit.

Since one would not say "The expression of a quantity is generally expressed," the above text is most easily understood if "The value of a quantity" is interpreted as $V_{A}$.

\subsection{Green Book, 2008}

Like the SI Brochure, the Green Book (3rd edition, 2008) [42] uses value in a way that is most easily understood with interpretation $V_{A}$ :

The value of a physical quantity $Q$ can be expressed as the product of a numerical value $\{Q\}$ and a unit $[Q]$

$$
Q=\{Q\}[Q]
$$

\subsection{VIM 3, 2008}

The following definitions of quantity value are from the third edition of the VIM, generally known as "VIM 3" [3]:

English:

quantity value

value of a quantity

value

number and reference together expressing magnitude of a quantity

French:

\section{valeur d'une grandeur}

valeur

ensemble d'un nombre et d'une référence constituant l'expression quantitative d'une grandeur

value of a quantity

value

Ensemble of a number and a reference constituting the quantitative expression of a quantity. 
In the English VIM 3, value is once again consistent with interpretation $V_{B}$, but the separation of magnitude from quantity that occurred in VIM 2 is retained. In French, valeur remains consistent with $V_{B}$.

A German-language translation of VIM 3 exists [4]. As noted on its back cover, the translation work was supported by representatives from the national metrology institutes of Germany, Austria, and Switzerland.

Although the VIM definition of valeur is accurately translated for Größenwert, a note under the definition of Einheit (unit) $[4,1.9]$ suggests that the translators' interpretations of Größe and Größenwert are not the VIM's definitions but are consistent with Fleischmann's:

\section{Maßeinheit}

Einheit im Messwesen

Einheit

reelle skalare Größe, durch Vereinbarung definiert und angenommen, mit der jede andere Größe gleicher Art verglichen werden kann, um das Verhältnis der beiden Größen als Zahl auszudrücken Anmerkung in der deutschsprachigen Fassung: Statt "Größe(n)" muss es hier korrekt "Größenwert(e)" heißen.

\section{Unit of measurement}

Unit in metrology

Unit

Real scalar quantity, defined and accepted by agreement, with which any other quantity of the same kind can be compared to express the ratio of the two quantities as a number.

Note in the German language version: Instead of "quantity(ies)" it should correctly read "quantity value(s)."

The same issue is raised in the German-language translation of ISO 80000-1:2009 [43] known as DIN EN ISO 80000-1:2013-08 [44], but in that standard the text of the definition itself was actually changed.

\subsection{Dybkaer, 2009}

Dybkaer performed a quite thorough survey and analysis of previous definitions before proposing the following formulation as part of his ontology [45]:

property value: inherent feature of a property used in comparing it with other properties of the same kind-of-property [45, §9.15]

quantity value: property value having a magnitude represented by a number and a reference $[45, \S 16.7]$

It is curious that a quantity value is described as having a magnitude, suggesting possibly interpretation $V_{C}$. But the next section supplies a simpler definition saying that a quantity value is a magnitude [45, §16.8]:

If nominal property values are not considered at all, a modified definition is necessary, such as

quantity value: magnitude of a quantity represented by a number and a reference

This is closer to $V_{A}$, but the additional text about how the magnitude is represented, which is a $V_{B}$ concern, unfortunately introduces a logical incoherence.

Like the VIM, Dybkaer cites and adheres to the definitional structure specified in ISO 704 (see Section 2.4). Given the semantics specified by ISO 704, this definition says that a quantity value is not the representation (number and reference); a quantity value is a magnitude, and the narrowing condition that distinguishes quantity values from non-values is that they are represented in the specific form of a number and reference.

This definition has the logical structure of " $C: A$ represented by $B$." The condition "represented by $B$ " is construed as a property that a particular $A$ would either have or not have. But one can define an infinite number of other representations that are not of the same form as $B$; e.g., a $V_{A}$ can be represented by a single symbol, a number-unit pair, or a more complex algebraic construct. So a particular $A$ can be represented in 
$B$ and non- $B$ forms at the same time, at which point this particular $A$, a single entity, is simultaneously a $C$ and not a $C$ depending on which representation of it you happen to be focusing on.

This incoherence is a general one that follows solely from the logical structure of the definition and the relationship between $A$ and $B$. It does not matter what is substituted for $A, B$, and $C$, and it does not matter whether the word "represented" is replaced with another word like "expressed," "indicated," "identified," or "denoted" that maintains the same referential relationship between $A$ and $B$.

There exist mature methods for detecting logical incoherencies like this in ontologies [46, 47].

\subsection{Mari et al., 2019}

Mari et al. proposed two definitions of quantity value corresponding to two different interpretations of quantity and magnitude [15, §6]:

... according to Position 1 values are individual quantities identified as multiples or submultiples of units, which are themselves individual quantities.

... according to Position 2 values are magnitudes identified as multiples or submultiples of units, which are themselves magnitudes.

Unfortunately, these are two more instances of the problematic " $C: A$ represented by $B$ " form of definition that was introduced by Dybkaer (see Section 4.19), which moves in the direction of $V_{A}$ but then confuses it with a $V_{B}$ concern.

\subsection{Kacker, 2021}

In a forthcoming paper, Kacker proposes the following [48]:

Quantity value is a definite magnitude that may be assigned to a quantity. $\ldots$

The JCGM 200 definition of a quantity value intermixes the concepts of a definite magnitude and its many possible expressions. So, we have introduced the term metrological expression for a number together with a metrological reference. A given quantity value (definite magnitude) may be represented by many equivalent metrological expressions.

Metrological expression is a number together with a metrological reference. A numerical expression is a number.

One can conclude from this text that quantity value corresponds to $V_{A}$ and metrological expression corresponds to $V_{B}$.

\section{Consequences of ambiguity}

The following subsections describe costs that have already been incurred by ambiguous interpretation of the metrological term quantity value. 


\subsection{Conflicts over the definition of unit}

The abstract denotation of a unit symbol within algebraic statements is not to be confused with the concrete meaning of the term unit that applies in narrative statements. One does not discard the material world when one defines a mathematical model of it. ${ }^{2}$ For base units or defining constants to serve their function of binding abstract values to reality, both concepts are necessary - call them what you will. Nevertheless, disagreement over which of these is properly assigned to the term unit in formal vocabulary has been vigorous.

Those who understand quantity value as $V_{A}$ might want to define unit as a quantity value, reflecting an algebraic focus. This is the configuration of Größenwert and Einheit in DIN 1313 . But the VIM defines quantity value as $V_{B}$. Applying the VIM's definition of quantity value to the former definition of unit results in a circular definition (a unit is a number and unit).

This is but a shallow technical glitch resulting from the mixture of two different conceptual models, but it upset the harmonization among multiple standards, including at least the SI Brochure, the VIM, and ISO 80000-1. So it came to pass that the insertion of "value" into the phrase "The unit is simply a particular example of the [value of a] quantity" during the drafting of the 9th SI Brochure brought out disagreement that ultimately led to the creation of the Consultative Committee for Units (CCU) Working Group on Core Metrological Terms (CCU-WG-CMT) [49].

This conceptual conflict, in some prior incarnation, was evidently on the mind of Dybkaer, who addressed the disagreement over the definition of unit very specifically in [45, §18.6.3]: "This definition and that of Fleischmann seem to claim that a unit is a value of a quantity. . rather than a special quantity, and that is not generally accepted." This claim is of course predicated on equating the German terms Größe and Größenwert to quantity and quantity value respectively. If we use current versions of DIN 1313 and the VIM as our German and English dictionaries, that equation does not hold, and the asserted claim is not an accurate representation of the intent of the cited texts.

\subsection{Anti-algebraic interpretation of quantitative expressions}

I describe an interpretation as algebraic if it produces a value type and operations on that type that may be consistently treated by the ordinary rules of algebra, anti-algebraic if special rules are needed or special restrictions apply.

The SI Brochure states that unit symbols are mathematical entities that may be treated by the ordinary rules of algebra [50, §5.4.1]. Under the ordinary rules of algebra, $1 x=x$. Nevertheless, the use of a standalone unit symbol, such as $\mathrm{kg}$ to indicate the same thing as $1 \mathrm{~kg}$, is deprecated in practice. This is reflected in $[50, \S 2.3 .1]$, where a 1 is included on the left hand side of every equation that relates an SI unit to defining constants. Why might this be?

In a concept system without a $V_{A}$, the multiplication of number times unit either is impossible to perform or yields only another number-unit pair, and a lone unit symbol has no algebraic interpretation. It is still possible to do quantity calculus, but the value type for these calculations is constrained to be exclusively the ensemble of number and unit together. With this conceptualization, the statement $1 \mathrm{~kg}=\mathrm{kg}$ is ill-formed.

In a concept system with a $V_{A}$, a unit symbol appearing in a quantitative expression denotes the $V_{A}$ that is simply the algebraic value corresponding to unit magnitude, by definition. Preceding a unit symbol by 1 is harmless but strictly speaking unnecessary. One can apply the ordinary rules of algebra consistently and without restriction.

Of course, one can include the concept $V_{A}$ but just refuse to allow an algebraic interpretation of unit symbols, in which case the interpretation of quantitative expressions becomes anti-algebraic and inconsistent with the SI Brochure only because of the added restriction.

Divergence in the interpretation of quantitative expressions has caused:

\footnotetext{
${ }^{2}$ A significant related discussion is the schism between "abstract" and "concrete" interpretations of quantities and units that is described in [23, §2.3.2].
} 
- A sad cycle of "memory hole" and "rediscovery" of the algebraic concepts, e.g., as acknowledged in the work of Carlson [51].

- Chronic instability of the English VIM's definition of quantity value accompanied by lengthy analysis $[7,15]$.

- An unproductive debate in CCU-WG-CMT over whether the equals signs appearing in the SI Brochure $[50, \S 2.3 .1]$ denote algebraic equality, correspondence, assignment, or definition [52].

- Further arguments over the definition of unit premised by assertions regarding whether the two sides of a quantity equation, e.g. $l=3 \mathrm{~km}$, necessarily denote the same kind of thing [53]. These arguments indicate as a corollary whether equality is to be understood in an algebraic or anti-algebraic way.

\subsection{Erosion of conceptual integrity}

The term conceptual integrity was popularized by Brooks [54, Ch. 4] to refer to a kind of consistency in computer architecture that allows the system to become a cohesive, sensible whole. He used European cathedrals as an analogy: the architectural unity of Reims served as an example of conceptual integrity preserved, in contrast to the disharmonious architecture of other cathedrals that juxtapose different architectural concepts that became fashionable during their construction. The passage of time and the hand-off of duties from one generation of builders to another tend to undermine conceptual integrity.

A similar form of conceptual integrity is a prerequisite of quality in explicit conceptual models, sometimes called ontologies [46, 47]. Loss of conceptual integrity in this context means that conflicting ideas have been baked into the model. This can lead to cumbersome use, misunderstandings, or in the worst case, logical incoherence.

Referring back to Section 4.12, Section 4.14, and Section 4.18, note the evolution of quantity value in the English VIM from

1. An expression of a quantity, to

2. The magnitude of a quantity, and then

3. An expression of the magnitude of a quantity

... while the corresponding definition in the French VIM stayed consistent with VIM 1.

Now, in discussions preceding the release of a first draft of VIM 4, it has been proposed to redefine quantity value in a form equivalent to Position 1 of Mari et al. [15, §6], slightly reworded: "individual quantity identified as the product of a number and a measurement unit..." [55]. As explained in Section 4.19, this form of definition introduces a logical incoherence.

The VIM 2 formulation, "magnitude of a particular quantity generally expressed..." avoided incoherence by making the form of expression only an example, not a prescription. But since that "generally" clause then does not constrain the definition, it is merely informative, and the definition reduces to "magnitude of a particular quantity." With the removal of magnitude from the proposed VIM 4 definition, introducing "generally" would make quantity value formally indistinguishable from individual quantity.

\subsection{Misdirection of software engineering}

In a well-factored implementation of quantity calculus in software, one can define a single class that encapsulates not only $V_{A}$, but also a probability distribution characterizing the uncertainty and possibly the kind of quantity as well. The algebraic operations that apply to instances of this class and the automatic propagation of uncertainty follow naturally [56].

This concept was quite difficult to communicate with the standard vocabulary defining quantity value to mean $V_{B}$ and not clearly enunciating the abstraction $V_{A}$ at all. Thinking in terms of a concept system that identifies $V_{B}$ but not $V_{A}$ literally causes poor design choices: 
- If the concept $V_{A}$ is incorporated, the design will support operating on quantity values without exposing details having to do with units or unit conversion. A unit needs to be specified only at the point when a value is expressed, and the unit chosen for any such expression has no inherent, permanent association with the value.

- If the concept $V_{A}$ is absent, quantity values are more likely to be implemented as a pair structure containing a numerical value and a unit identifier, or even as a numerical value with a specific unit prescribed. Since the details having to do with units and unit conversion are unnecessarily exposed, brittle code can be written that breaks if the units identified are not what was expected. The potential consequences of this encapsulation failure are well-known [57].

This is an example of a case where a linguistic compromise can lead to bad engineering, as if the design of a car were inferred from the now-obsolete term "horseless carriage."

\section{Conclusion}

This report has documented the historical background of divergent understandings of the term quantity value and described consequences that the inconsistency has had.

It is poignant that some writings in metrology burden the algebra of physical quantities with definitions and assumptions that are anti-algebraic, but those who have learned to operate within the confines of that language are not suffering. The conceptual model has no impact on the operation of a metrology laboratory for physical calibrations, only occasionally on the rules and style conventions for how quantitative statements are to be expressed. The negative impact is realized instead in academic and standards work as exemplified in Section 5, and in information technology work when a well-factored conceptual model for quantity calculus becomes an engineering requirement.

With the benefit of modern formal methods, it is a simple matter to define a logically coherent conceptual model in which all of the quantity value concepts are included; but to move standards in that direction is anything but simple. A single definition that can be interpreted whichever way the reader desires has the advantage of a specious simplicity around which an apparent consensus readily forms. To persuade stakeholders to understand and support a formal model when they have not yet attributed a tangible cost to the ambiguity of language in general use is very difficult.

It is a normal occurrence in standards work to discover that there are multiple concepts in play and then work to identify and differentiate them. A standard fit for a global audience cannot emerge from sectarian conflicts over control of particular terms; nor can it emerge from exclusion or indifference to negative externalities. Reason must prevail.

\section{Acknowledgments}

The historical trace owes much to an earlier history by de Boer [23], who identified many of the significant references that needed to be reviewed.

The view of the current situation owes much to personal communications with colleagues at NIST, participants in the CCU-WG-CMT, and other experts who have debated the definitions of core metrological terms.

\section{References}

[1] BIPM/IEC/ISO/OIML. International vocabulary of basic and general terms in metrology (VIM), 1st edition, 1984. Amended in 1987.

[2] ISO Guide 99:1993. International vocabulary of basic and general terms in metrology (VIM), 2nd edition. 
[3] Joint Committee for Guides in Metrology. International vocabulary of metrology-Basic and general concepts and associated terms (VIM), 3rd edition, 2008. Amended in 2012, JCGM 200:2012, https: //www.bipm.org/en/publications/guides.

[4] Burghart Brinkmann. Internationales Wörterbuch der Metrologie-Grundlegende und allgemeine Begriffe und zugeordnete Benennungen (VIM)-Deutsch-englische Fassung. Beuth, August 2012. 4. überarbeitete Auflage, ISO/IEC-Leitfaden 99:2007, https://www . beuth.de/en/publication/ internationales-woerterbuch-metrologie-vim-/147547918.

[5] Bertrand Russell. The Principles of Mathematics. Cambridge University, 1903. Online edition available at https://people.umass.edu/klement/pom/.

[6] David A. Schmidt. Denotational Semantics: A Methodology for Language Development. 1997. Previously published by Allyn and Bacon (1986) and William C. Brown (1988); now available at https://www . scss.tcd.ie/Andrew.Butterfield/Teaching/CS4003/DenSem-full-book.pdf.

[7] Luca Mari and Alessandro Giordani. Quantity and quantity value. Metrologia, 49(6):756-764, 2012. https://doi.org/10.1088/0026-1394/49/6/756.

[8] Eran Tal. Individuating quantities. Philosophical Studies, 176:853-878, 2019. https://doi.org/10. $1007 /$ s11098-018-1216-2.

[9] Rudolf Fleischmann. Einheiteninvariante Größengleichungen, Dimensionen. Der Mathematische und Naturwissenschaftliche Unterricht, 12(9:385-399 and 10:443-458), 1960.

[10] Joel Michell and Catherine Ernst. The axioms of quantity and the theory of measurement: Translated from Part I of Otto Hölder's German text "Die Axiome der Quantität und die Lehre vom Mass". Journal of Mathematical Psychology, 40(3):235-252, September 1996. https://doi.org/10.1006/jmps.1996. 0023.

[11] Louis Couturat. Les Principes des Mathématiques. Félix Alcan, éditeur, Paris, 1905. Available from Google Books, https://books.google.com/books?id=IC_J6gJXMwQC.

[12] Dictionnaire de l'Académie Française. 9th edition, 2020, work in progress. https://www. dictionnaire-academie.fr/.

[13] ISO 704:2009. Terminology work-Principles and methods, 3rd edition, 2009-11-01.

[14] Unified Modeling Language specification, version 1.5. OMG document formal/2003-03-01, Object Management Group, https ://www.omg.org/cgi-bin/doc?formal/2003-03-01, March 2003.

[15] L. Mari, A. Chunovkina, and C. Ehrlich. The complex concept of quantity in the past and (possibly) the future of the International Vocabulary of Metrology. Journal of Physics: Conference Series, 1379, 2019. https://doi.org/10.1088/1742-6596/1379/1/012004.

[16] James Clerk Maxwell. A Treatise on Electricity and Magnetism, volume 1. Clarendon Press, 1873. https://en.wikisource.org/wiki/A_Treatise_on_Electricity_and_Magnetism.

[17] Oxford English Dictionary. Oxford University Press, 2nd edition, 1989.

[18] Oxford English Dictionary. https://www.oed.com/ (online entry updated September 2011 for the third edition, which is a work in progress).

[19] Dictionnaire de l'Académie Française. 8th edition, 1935. https://www.dictionnaire-academie.fr/.

[20] Duden Wörterbuch, 2020. https://www.duden.de/.

[21] Peter Mohr. Personal communication (email), March 2021.

[22] Michael P. Krystek. Maxwell on quantities and units. Working group document WG-CMT-20-07, Consultative Committee for Units Working Group on Core Metrological Terms, March 2020. https: //www.bipm.org/en/committees/cc/ccu/wg/ccu-wg-cmt. 
[23] J. de Boer. On the history of quantity calculus and the international system. Metrologia, 31(6):405-429, 1995. https://doi.org/10.1088/0026-1394/31/6/001.

[24] Hermann von Helmholtz. Zählen und Messen, erkenntnisstheoretisch betrachtet. In Wissenschaftliche Abhandlungen, volume 3, chapter CXXIX, pages 356-391. Johann Ambrosius Barth, Leipzig, 1895. Available from Google Books, https://books.google.com/books?id=NTIRAAAAYAAJ.

[25] Alfred Lodge. The multiplication and division of concrete quantities. General Report (Association for the Improvement of Geometrical Teaching), 14:47-70, January 1888. https://www . jstor.org/stable/ 24681261.

[26] Alfred Lodge. The multiplication and division of concrete quantities. Nature, 38:281-283, July 1888. https://doi.org/10.1038/038281a0.

[27] Julius Wallot. Dimensionen, Einheiten, Maßsysteme. In Handbuch der Physik, volume 2, chapter 1, pages 1-41. Springer, Berlin, 1926.

[28] DIN 1313. Schreibweise physikalischer Gleichungen, November 1931.

[29] DIN 1313. Schreibweise physikalischer Gleichungen in Naturwissenschaft und Technik, September 1962.

[30] René Dybkær and K. Jørgensen. Quantities and Units in Clinical Chemistry. 1964.

[31] René Dybkær and K. Jørgensen. Quantities and Units in Clinical Chemistry (including Recommendation 1966 of the Commission on Clinical Chemistry of the IUPAC and of the IFCC). Williams \& Wilkins Co., 1967.

[32] IUPAC/IFCC. Quantities and units in clinical chemistry (Recommendation 1973). Pure and Applied Chemistry, 37(4):517-546, 1974. Available at https://old.iupac.org/publications/pac/1974/pdf/ $3704 \times 0517$.pdf.

[33] IUPAC/IFCC. Quantities and units in clinical chemistry (Recommendations 1978). Pure and Applied Chemistry, 51(12):2451-2479, 1979. Available at https://old.iupac.org/publications/pac/1979/ pdf/5112x2451.pdf.

[34] Georges Férard, René Dybkaer, and Xavier Fuentes-Arderiu. Compendium of Terminology and Nomenclature of Properties in Clinical Laboratory Sciences: Recommendations 2016. Royal Society of Chemistry, 2016. https://doi.org/10.1039/9781782622451.

[35] DIN 1313. Physikalische Größen und Gleichungen: Begriffe, Schreibweisen, April 1978.

[36] ISO 31/0:1981(E). Quantities and units-General principles concerning quantities, units, and symbols, 2nd edition, 1981. https://www.iso.org/.

[37] Luca Mari. Personal communication (meeting), 2018.

[38] E. Richard Cohen and Pierre Giacomo. Symbols, Units, Nomenclature and Fundamental Constants in Physics. IUPAP Commission C2 (SUNAMCO), IUPAP Secretariat, London, 1987. 2010 reprint, https://iupap.org/wp-content/uploads/2014/05/A4.pdf.

[39] DIN 1313. Größen, December 1998.

[40] BIPM. The International System of Units (SI), 8th edition, 2006. https://www.bipm.org/en/ publications/si-brochure/.

[41] PTB. Das Internationale Einheitensystem (SI), 8th edition, February 2007. https: //www.ptb.de/cms/fileadmin/internet/publikationen/ptb_mitteilungen/mitt2007/Heft2/ PTB-Mitteilungen_2007_Heft_2.pdf.

[42] E. Richard Cohen et al. Quantities, Units and Symbols in Physical Chemistry. IUPAC and RSC Publishing, Cambridge, 3rd edition, 2008. 2nd printing, https://iupac.org/wp-content/uploads/ 2019/05/IUPAC-GB3-2012-2ndPrinting-PDFsearchable.pdf. 
[43] ISO. Quantities and units-Part 1: General, 1st edition. ISO 80000-1:2009(E), https://www. iso.org/.

[44] DIN EN ISO 80000-1:2013-08. Größen und Einheiten-Teil 1: Allgemeines, August 2013. https: //www. beuth.de/.

[45] René Dybkaer. An ontology on property for physical, chemical, and biological systems, 2009. https: //doi.org/10.1351/978-87-990010-1-9.

[46] Nicola Guarino and Christopher Welty. Evaluating ontological decisions with OntoClean. Communications of the ACM, 45(2):61-65, February 2002. https://doi.org/10.1145/503124.503150.

[47] María Poveda-Villalón, Asunción Gómez-Pérez, and Mari Carmen Suárez-Figueroa. OOPS! (OntOlogy Pitfall Scanner!): An on-line tool for ontology evaluation. International Journal on Semantic Web and Information Systems, 10(2):7-34, April-June 2014. https://doi.org/10.4018/ijswis. 2014040102.

[48] Raghu N. Kacker. Towards revision of JCGM International Vocabulary of Metrology. Submitted to IMEKO 23 World Congress (result pending), August 2021.

[49] Consultative Committee for Units Working Group on Core Metrological Terms. https://www.bipm . org/en/committees/cc/ccu/wg/ccu-wg-cmt.

[50] BIPM. The International System of Units (SI), 9th edition, 2019. https://www.bipm.org/en/ publications/si-brochure/.

[51] Donald E. Carlson. A mathematical theory of physical units, dimensions, and measures. Archive for Rational Mechanics and Analysis, 70:289-305, December 1979. https://doi.org/10.1007/BF00281156.

[52] Richard Brown, rapporteur. Minutes of the virtual meeting of WG-CMT on 6 and 7 July 2020, Rev2. Working group document WG-CMT-20-20, Consultative Committee for Units Working Group on Core Metrological Terms, November 2020. https://www.bipm.org/en/committees/cc/ccu/wg/ ccu-wg-cmt.

[53] Consultative Committee for Units (CCU) Report of the 24th meeting, October 2019. https://www . bipm.org/utils/common/pdf/CC/CCU/CCU24.pdf.

[54] Frederick P. Brooks Jr. The Mythical Man-Month: Essays on Software Engineering. Addison-Wesley Professional, 2nd edition, 1995.

[55] Charles Ehrlich. Comparison of VIM4 and VIM3 definitions for select entries. Working group document WG-CMT-20-13, Consultative Committee for Units Working Group on Core Metrological Terms, July 2020. https://www.bipm.org/en/committees/cc/ccu/wg/ccu-wg-cmt.

[56] David Flater. Architecture for software-assisted quantity calculus. Computer Standards \& Interfaces, 56, February 2018. https://doi.org/10.1016/j.csi.2017.10.002.

[57] Robin Lloyd. Metric mishap caused loss of NASA orbiter, September 30, 1999. http://www.cnn. com/ TECH/space/9909/30/mars . metric.02/index.html. 